\title{
E-learners or E-actors: Exploring the Possible Cultural Barriers Impacting Learner's Participation Originality in Online Collaborative Learning
}

\author{
Anietie G. Ukpabio \\ 1.Doctoral Researcher of PhD in E-Research and Technology Enhanced Learning Lancaster University. \\ Lancaster, UK \\ 2.Business Analyst at IBM Client Innovation Centre. Leicester, UK
}

\begin{abstract}
Educationally, technology-enhanced collaborative learning is the use of technology to support/mediate online collaborative learning with some degree of ease. In other words, this paper focused on the notion that during online collaborative learning, learners are unconsciously compelled (as a result of their primary cultures) to forge a new self-identity to enable them participate and cope with learning with their peers.Using a literature review methodology, this paper argued using carefully selected literature and theories towards answering questions like the cultural barriers as well as the socio-technical dynamics that hinders the success of online collaborative learning. Although much remains to be explored, conclusions were drawn based on the findings that relate to the social and asocial character of online learning, the fear of fear of peers, the fear to be misunderstood, culturedependent beliefs and a low order of discourse and challenges among peers.
\end{abstract}

Keywords: Technology-enhanced, learning, collaborative learning, e-learners, e-actors, self-identity, culture, socio-technical, beliefs

DOI: $10.7176 / \mathrm{JEP} / 10-11-01$

Publication date: April $30^{\text {th }} 2019$

\section{Introduction}

In an online learning scenario, there is a tendency for learners to be globally distributed; learning gradually becomes culturally diverse. Although, this does not imply that the traditional bricks and mortar learning scenario lacks diversity in context, in fact, any given course would have to be diverse or homogenous to a certain extent in order to include all learners. While the potentials of global, culturally diverse collaboration are regularly stated as an immediate advantage of e-learning, learners from various social backgrounds learn or interact in various ways. What is considered to be a vital concept to learn, and as effective teaching and learning practices, are socially built collaboratively. In online learning settings consisted of learners from various social backgrounds, it is vital that course facilitators know about individual learner's social backgrounds with a precise outcome to create or adjust plans suitable for the learner's social learning systems. Also, course facilitators need to be mindful of how social thoughts might be repeated about teaching and learning and the unsuitability for all learners (Capdeferro and Romero, 2012).

Social presence identifies with the necessity for learners of technology-oriented interaction to acknowledge one another as actual humans. Minimal social presence can become a specific problem in online collaborative learning scenario, for example, discourse boards, prompting an emotional state of detachment and withdrawal from online learning (Zhu, 2012).

\subsection{The Problem Statement}

Almost frequently, the online learning experience of learners can be motivated by the degree to which their culture is not changed by various factors of online learning. Learners occasionally find it hard to cope because of the formation of a new self-identify that bears no resemblance to what the learners are in a face-to-face (offline) situation. In the context of this study, they become e-actors (i.e. not e-learners but pretending to assimilate in an online collaborative learning). It is worth considering culture in e-learning platforms that involve learning through interactions, communication and interpretations with diverse learners (Zhu, 2012). These platforms are usually based on shared qualities, opinions and social activities. There are two essential ways that culture influences learners' participation originality in constructivist educational settings: confusions in interaction and collaboration, and constructivists' emphasis on what is considered as "genuine" learning problems.

To emphasise more about the cultural influences on learners' participation originality, the misconceptions in interaction and collaboration is referred to: the cultural foundations of learners firmly impact their ways of interaction (either directly or indirectly) and methods of collaborating with other learners (either independently or collaboratively). Culture is also embedded in learners' varying desires of how to learn collaboratively in a team. Culture also shows in a learner's manner of interaction - In a study carried out by Kaye (2012), Taiwanese learners report that American students are overly "belligerent" in their manner of interaction. Additionally, the 
subjective learners' opinions and experiences of "genuine" learning tasks. Constructivist learning designs are usually based on creating "genuine" learning tasks that are applicable and consequently appealing to learners. A significant obstacle to culturally diverse social constructivist analysis is discerning if learning tasks are "genuine" to learners from diverse cultural background. In other words, whilst one culture emerges as the default and dominant one, others are expected to accept it and integrate themselves, or drop-out. Furthermore, it can be said that the worst case scenario for e-actors is cyber truancy (electronic absenteeism). Although, whilst cyber truancy is a concept worth exploring, it is not a focus of this study, therefore it is inconclusive to imply that cultural barrier is one of its major influencing factors.

\subsection{Defining e-Learners, e-Actors and Participation Originality}

Traditionally, e-learners connote a term used to describe learners that utilise technology towards the acquisition of knowledge. Although the term 'e-learners' may seem too diverse to be largely suitable in the context of this study, it is invoked only to conceptualise the group of learners whose cultural background intensifies their ability to harmonise in an online collaborative learning activity, without the formation of a new self-identity. This group of learners is considered to have a high participation originality in collaborative learning activities. Reversely, eactors is an embodiment of a group of learners whose cultural dimensions originates and or exacerbates their inability to harmonise in an online collaborative learning activity. This group of learners is considered to have a low participation originality in online collaborative activities. Beyond culture, many factors can shape the outcome of online collaborative learning, but to sceptically acknowledge that amid the existence of other numerous impacting factors, culture is tangential to collaborative learning. Although, this can be deemed as concurrent to a significant exaggeration of the truth.

\subsection{Study questions}

To emphasise more about the opening debate above (see section 1.1), this study focused on exploring the existing cultural problems identified with online collaborative learning and to understand better how these problems can be mitigated. The objectives of the research were submerged in the main and sub-research questions which were to start with a broad question that inquires what the possible cultural barriers to learners' participation originality in online collaborative learning are? Beyond this main question, it was essential to maximise the advantage of such a relatively broad question by complementing it with an important follow-up (sub) question which helped in the development of themes and reinforced the narrative thread section of the literature review. The question was:

Is the difference between online and offline barriers driven by the technology or socio-technical dynamics of online learning?

Similarly, in line with the recommendations of a few scholars (like, Patton, 2002; Cresswell, 2009), which emphasised that study method should be shaped by the research aims and questions, a qualitative method was adopted for this study. Predominantly, a technique of associating the study questions to the issues in the context and a further association with the past and evolving themes in existing literature was adopted. A more thorough account of the process, elements, and circumstances that informed this technique is outlined in the research methodology section of this report (see section 3).

\section{Review of relevant literature}

Amid the researchers researching technology-enhanced learning, over the past decade, a group has emerged called the computer-supported collaborative learning (CSCL) (Bodemer and Dehler, 2011; Järvelä and Hadwin, 2013; Phielix et al., 2010). In a strong move towards characterising this research paradigm, Kumar (2010) disputes that the previously existing types of educational research of culture and technology scoped learning and teaching as mental problems (can be seen as a behavioural or intellectual problem) and, in that capacity, can be studied by the conventional techniques for psychological experimentation.' In essence, they concentrate on the consciousness of the individual learner as the element of study when searching for instructional results, cognisance or meaning-making and learning. By difference, the CSCL theory 'is based on the research conventions of those fields of study - sociology, communication science, semantics, anthropology - that are dedicated to the study of culture, language as well as different dimensions of social scenario. This sudden shift in paradigm, concentrating on 'the cultural and social settings as the study focus, gives rise to a lack of a common measure in principle and practice associated with pre-existing standards.

The lack of a common measure amongst CSCL and other ideal models of technology-enhanced learning can be better understood if a decision is made to define it thus from the perspectives of CSCL, as the individual learner learns and distinctively thinks as less as the collaborative group also does. Because for over the past centuries, the academic community has arguably grown accustomed to looking at learning and teaching as exercises of individual personalities, it is hard to consider them as basically group exercises (Kumar, 2010). 


\subsection{Shared Meaning but Unshared Understanding}

The debate stimulated by Rogat and Linnenbrink-Garcia (2011) about shared meaning theory attempted to give meaning regarding the form of group perceptions. The contentions it put forth were from the perspective of shared group meaning as well as individual understanding. Shared meaning, on the other hand, was not any less seen as mental representations stored in the minds of learners. Mental substances of such magnitude must be construed from reflection and the translation of communication and conduct of individuals, while culturally shared meaning can be seen in the obviously exhibited discussions that happen in group communications, as well as nonverbal communication and related objects. This procedure does not bring about a behaviourist refutation of the human thinking process in blocking out indirect mental conditions and concentrating on noticeable relationships, as a result of the methodological acknowledgement of interpretive perspectives. Individuals are viewed as translating subjects, who apart from responding to stimuli also comprehend its implications. Beyond a debatable point, the interpretation of meaning is a task most accomplishable by humans (Hadwin et al., 2011).

Although, this does not suggest that group understandings is only some sort of measurable average of individual psychological understanding, a central stance within established views, or an intertwining of inward representations. The construction of a group meaning is done by the associations of the individual members of the group, and not by the individuals alone. It is a rising property of the discussion and collaboration. This is not minimised to thoughts or understandings of people. Rogat and Linnenbrink-Garcia (2011) demonstrated a case of how this functions. The discussion interpreted that there is unusually curved, projective and indexical; that implies that it infers and needs a (maybe open-ended) arrangement of references to conclude its significance. These references are progressively an element of the history and conditions of the discussions than of expectations inferable to particular learners in the group.

Indeed, it is only distinct thoughts and objectives (which are partly shaped by culture) that one can attribute to the individual learners after one has widely translated the implications of the discussion in general.

In other words, it can be implied that learners learn due to the group learning procedure and that the only way learning can take place in a group is by (unrealistically) guaranteeing that the participants learn. Obviously, the sort of "learning" that takes place in a short communication is far from the learning that lecturers seek over a long time. It may be suitably called 'knowledge constructing', connotes the act of verbal communication evolving into a new context (or culture dependent) shared meaning. To comprehend what happens during collaborative learning, it appears to be quite necessary to be plainer as regards the method of shared information - the manner of production, arrangement, dissemination and assumption (Friedman, 2015).

The real problem when it comes to the comprehension of shared information and group understanding is the fact that it is sporadic to ascribe opinions and intents of individual members - and to consider the group dynamics and ascribe to it from the scope of the actions (or inputs) of individual group members. It is expected that the words of a speaker are very much characterised ahead of time in the mind of the speaker and that speaking is only a manner of expression to pass on some speaker-subjective meaning on to the audience. This notion exposes a contention. If meaning is culturally built, why do researchers feel the need to regard it as a personal possession; if it happens in remote personalities, how then could it be possibly shared and understood collaboratively?

The likelihood of shared meaning must by one means or another be clarified. This is especially crucial in instances of online collaborative learning, where the knowledge co-constructed needs to be mutual among the participants (or might be mutually shared in general, before it is viewed as a segment of an individual's learning) (Friedman, 2015).

\subsection{Common Ground but Uncommon Issues}

Traditionally, within the theory of computer-supported collaborative learning (CSCL), it is imperative to refer to the theory of 'shared belief' to clarify how shared understanding is conceivable. To begin with, Phielix et al., (2010), stated that teamwork requires shared understanding amid team members, introduced through a procedure of 'grounding' (a simpler trust pedagogy). It can be arguably infered that viable interaction is for the most part based on the sharing of a language, of an enormous experience and information about the working of things (in both the physical and social environment) of numerous social practices, implied within collaboration and of an overall understanding within a mutual context of themes, objects, things, past happenstances, past associations. The act of sharing is owing to the socialisation in a typical culture or intertwined sub-cultures. Most shared believes are underestimated as a major aspect of being human. The phenomenological hermeneutics of Bodemer and Dehler (2011) and Järvelä and Hadwin (2013) - expanding on the customs of Bodemer and Dehler demonstrated unequivocally the manners in which human comprehension and capacity to translate meaning depend upon a mutual social perspective.

Although it stressed the significance of interpretation to human existence as being involved in the world, it also deliberated on situations where the 'common ground' failed. This included examples like deciphering historical calligraphy or interpreting foreign dialects or religious beliefs - for instance, in what capacity can 
Christians comprehend the religion of Christianity beyond the worship of a supernatural being? Alternatively, do all Christians believe in the idea of the trinity? The existing deliberations of 'common ground' in CSCL are, notwithstanding, more engaging. It focuses on the momentary dialogue of shared belief during momentary collaborations. Such arrangement is especially noticeable when a breakdown of the shared belief exists, a clear challenge in the shared understanding. Almost frequently, a breakdown occurs when members try to address the misconception or absence of commonality in the belief. For example, in Sharples et al., (2010) and Wickeri (2011) publications, a great part of the translated dialogue was examined as an attempt to achieve shared understandings in circumstances where group interaction had turned challenging.

It is not understood if breakdown repairs in such common ground originated from thoughts that formed in the mind of one person and are then transferred to other individuals until an agreement is reached, or if the common ground may be made in the interaction of the group in general (i.e. as a result of mere coincidence). It is conceivable that mutual understanding can occasionally be best clarified in one form and at times another. However, it appears that the inquiry as to the origination of shared understanding ought to be handled as an exact question in general. One which this study does not focus solely on. The theory of common ground referenced to by Arkoudis (2010), Haslanger, (2011) in CSCL originates from the theory of Clark and Brennan (1991). Clark and Brennan (1991) position their findings unequivocally in the conversation analysis (CA), despite the fact that their theory has an unusual mentalist sense that is unusual of CA. They contend that collaboration, interaction and 'every shared activity is based on common ground and its collection'. Progressively, reforming this shared belief on a momentary basis in the discussion is known as 'grounding'. According to this theory, grounding is a collaborative procedure by which members attempt to achieve common ground. It is believed that shared understanding (also known as shared belief) will always be imperfect (i.e., the members can on no account have convictions that are totally the same). It serves that 'the speaker, as well as his or her associates commonly, trust that the members understand what the speaker intended to an extent adequate for existing context and reasons. Clark and Brennan (1991) further demonstrate how different conversational shifts between sets of individuals can direct this sort of grounding and accomplish a possible level of commonality of belief. They further demonstrate how distinct technologies (like a computer) support facilitation of the grounding procedure in various manners.

Referring to Clark and Brennan (1991) contribution theory, where a member adds a peculiar belief as a suggested expansion to the existing common ground and further participate in discussing the belief until all members consider the new belief as a norm (or a new part of the existing common ground), this act often leads to the expansion or an update of common ground which attracts more members. Along these lines, it is assumed that Schegloff (1991) reacted controversially to Clark and Brennan (1991) by contradicting the practice of ethnomethodology and CA to this theory of mental philosophies: Schegloff calls attention to the fact that Garfinkel (1967) 'asked what precisely may be expected by such ideas as "common" or "shared" information. Schegloff further proposed a theory of repair in verbal interaction that appeared different to that of Clark's by interpreting what occurred as a cultural practice modelling cultural forms of communication. As indicated by Schegloff's publication, repair is seen as a type of culturally shared perception that happens during discussions, taking after recognised conversational forms, as opposed to exchange and evaluation of beliefs between realistic thinking individuals.

\subsection{Culture Fluidity or is it Simply a Trust and Thrust Issue?}

The fluidity of culture is an intricate topic when discussed in studies. For the purpose of narrowing the focus of this study, the elements of the fluidity of culture that are urgently imperative to understanding the phenomena under study is discussed briefly.

Culture transforms the views, values, perceptions and behaviours of people associated to it (McSweeney, 2002). It appears as an insightful structure that constructs meaning to various interactions and interpretations (Morse, 2003). Whilst the fluid nature of culture exacerbates the inability to track or reveal the distance travelled or the degree of transition made by a learner towards assimilating into a certain culture, there exist studies that stressed that individualist and collectivist cultures do not only sway various self-awareness of learners but as well their cognitive processes (Nisbett, 2003). Learners with individualistic cultural perspectives (culture of thrust) tend to be more frankly spoken, opinionated or even appear to be aggressive (they can be categorised as e-learners); however, learners from collectivistic cultures (culture of trust) tend to avoid getting involved in confrontations that could lead to conflict (they can be categorised as e-actors). They often make use of more intermediaries as a means of transportation for their communication. The former category of culture implies a higher esteem for independence and the latter category implies a greater esteem for power. The individualistic culture (colloquially called Flemish culture), is common in Western scenery, while previous researchers acknowledged that the Chinese culture (colloquially called Confucian-heritage cultures) is customarily a characteristic of a collectivistic culture (Kouzakova, 2012; Hofstede, 1986). In other words, it would appear that learners from the culture of trust prefer to slowly establish a connection among peers (either directly or through 
intermediaries) by trust before engaging fully in online collaborative learning. While learners from the culture of thrust would prefer engaging in a connectionless state (direct approach). The speed and effort used to establish a connection among peers become some of the major factors that characterise these group of learners.

To totally posit this in an online collaborative learning scenario, learners from the culture of trust (e-actors) would rather prefer to conceal their social presence with less information provided in personal profiles, not want to be confronted or confront others. While they lay low behind their screen and keyboard, they would prefer to see more of their colleagues' (i.e. learners from the culture of thrust) social presence without interacting to help build their low trust level. This further helps them decide a 'trust pedagogy' of what kind of information to share first and how each information is to be shared.

Consequentially, while the phrase 'culture of thrust' is most consistent with an arguably contextuallyderogatory act of unfriendly engagement and interaction with peers, English language becomes a constraint towards articulating this hypothesis properly, the phrase "culture of thrust" is not sufficient to the intention of this study. To start with, "thrust" although not always appropriately, typically has a derogatory inference in this context. Learners who collaborate on the principle of thrust often have the profound sense that there are no stages or phases of engagement or interaction. To admit that there are stages and phases of peer engagement and interaction is deemed as concurrent with admitting weakness in their social abilities.

Beyond the 'collectivist versus individualist' concept, 'power distance' (high versus low) is an additional significant cultural factor, which stipulates how power is unequally distributed and the extent to which less influential individuals in the world admit dissimilarity in power. Previous studies (e.g. Foster et al., 2014; Koschmann et al., 2011) indicated that in cultures that are deemed as high power distance, learners appear to be very inactive and may be hesitant to partake in collaborative activities because they are not fond of dialogues in the presence of their peers. Previous studies reveal that cultures like the 'Chinese' tend to be higher on power distance when compared to various countries like the 'Western countries' (Edmundson, 2007). Although, a close examination of the contemporary cultural and educational settings that includes the power distance between learners and course facilitators is seemingly essential for comprehending the present circumstances, power distance and learners' ideal preferences for online collaborative learning in the concerned settings.

Although, whilst the essentialist perspectives discussed in this section do not represent the fluid nature of culture. It is not clear if various traits of cultures are totally considered by categorising cultures in collectivist and individualistic cultures. It can be argued that a learner may possess both traits in an equal proportion or in an unequal proportion. The justifications that makes a learner worthy of being typified into a category is debatably implausible. Furthermore, Hofstede (1986) work does not account for the individuals but provide a general category of culture in learning.

Critically, it would debatably appear that both learner categories may share a central stance regarding feeling dissatisfied and disengaged in an online collaborative activity that fails to instil in them the sense of learning ownership (i.e. they learnt it on their own rather than it was learnt for them). To irradiate this point, an analogy of a driving lesson is adopted to demonstrate that an aspiring driver that learns about road signs and rules without handling the wheels is likely to feel dissatisfied and lack of learning ownership as compared to an aspiring driver that learns about road signs and driving rules by handling and meandering the wheels.

\subsection{Social Animals Interact in an Unsocial Habitat}

The impacts of culture on the experiences of learners in online collaborative learning settings can be especially intense. Culture significantly influences cultural conduct (as well as what is seen as proper or improper conduct), interaction, perceptive procedures, and how a learner relates to learning innovations, for example, computers (Vatrapu, 2008). Because these tools are all integral to technology enhanced learning plans, the design of online collaborative activities is thus culturally biased. Vatrapa states that 'socio-technical affordances vary across cultures.' Vatrapa characterises 'socio-technical affordances' as possibilities to take action and 'opportunities to make meaning' in a socio-technical framework in respect to the activity capacities and the capability of the actor to make meaning."

Progressively, the differences in how culturally-diverse learners fit these affordances resonate with culturally diverse variances in subjective procedures. Nisbett (2003) shows that how humans compose and comprehend visual and written texts differ distinctly - usually plainly. Masuda and Nisbett's (2001) when evaluating American and Japanese views of photographic data uncovered vital contrasts in how American and Japanese natives view and interpret photographic data. The Japanese concentrated on the links between various visual components and produced distinctive yet "logical" explanations of the photographic data. The Americans concentrated mostly on the distinct aspects of the pictorial data and turned out to be more adept than the Japanese at identifying the distinct aspects of the pictorial data when it was presented to them again in a different manner.

Additionally, Vatrapa (2008) stated that manners and approaches of interaction differ distinctly among learners and were almost identical to the kind of online program that the learners were studying. In a study that 
involved American and East Asian graduate learners all enrolled on an identical online learning-based program on global health at the University of Hawaii, Vatrapa (2008) observed that Anglo-American learners made considerably more individual commitments, were more open to talking about data sharing approaches or methods, and were additionally more prone to expressly deliberate meaning-making procedures or strategy. Vatrapa (2008) determines that online learning programs should devise an alternative means that would accommodate all learners, this conclusion led to the invocation of the term "alternates for action." This would guarantee the best learning results for every learner - not only the learners who have an identical cultural foundation as the program design. Chen et al. (2006) also report major dissimilarities in the communication styles of American and Taiwanese learners. Though the responses of American students on discourse threads were short and continuous, Taiwanese learners responded in the later phases of the interactions - which the American learners saw as a flaw (Chen et al., 2006).

\section{Methodology and Method}

Principally, this study was underpinned by a literature review as a methodology. Almost frequently, researchers when taking part in qualitative literature review are usually dependent on a specific method of literature selection that gives rise to a context that is an embodiment of all scenarios that are referenced in their research plan (Poulis et al., 2013). The choice for this research was changed from a technique that is suitable for all circumstances to choosing written works that provided an in-depth analysis of the occurrences under study. Predominantly, a certain importance was put on choosing literature related to the hypothesis and understanding of cultural barriers of online collaborative learning as well as written works that emphasised the outcomes of effective online collaborative learning that were as a result of mitigating the cultural barriers. Moreover, given that secondary data was obtained through literature review, this additionally prompted the use of the phrase 'narrative review" (Xu and Connelly, 2010). The significant factors of the data collection tools were attributed to the nature of the research problems, the rarity of the fundamental assumptions and the presence of diverse opinions in the chosen literature. A highly detailed explanation of the methodology and experiences used during the secondary data collection process is expressed in the next section beneath (see section 3.1).

\subsection{Selecting and Using The Literature}

Primarily, a major understanding of the context surrounding the theme and basic terms habitually used to discuss the subject was carried out. This provided substantial knowledge that helped ascertain some terminologies. However, the preliminary list of terminologies produced seemed to be anything but comprehensive, associating the terminologies to key phrases present in the study questions yielded considerable insights towards eliminating (or shortlisting) relevant terms. There was also a generation of synonyms of the terms. Following to the generation of synonyms was the documentation of resources to be searched. Regrettably, irrespective of the concept being studied, there is no one single source of information that would contain all the major elements required for the research. This actual search exercise was initiated by searching through resources on Lancaster University online library (alternatively referred to as OneSearch). Eventually, through the Lancaster University virtual private network (VPN) access was granted to some other libraries as well as some full-text educational papers on Google Scholar.

Systematically, my search focused on terms that met the inclusion criteria (see below for inclusion criteria) while less emphasis was laid on the exclusion criteria only to remind me of terms that were not worth searching. At some point in the search exercise, I adopted techniques that involved the use of special characters (also known as wildcards or wild characters), operators and escape characters in my search strategy, such as "or," "and," "not" and an asterisk (*). More significantly, the literature was filtered by recentness between five to ten years of age. However, given that the theoretical framework from which this research was scoped through is relatively historical, it was difficult to disregard studies that were conducted more than ten years ago. Finally, the articles chosen were organised, appraised and associated in order to enhance the chain of evidence.

\subsection{Inclusion Criteria}

- $\quad$ Recent studies that matched the research context and ranged between five to ten years old;

- $\quad$ Studies that associated culture to online learning;

- $\quad$ Studies that focused on online collaborative learning;

- $\quad$ Studies that focused on the social aspects of online learning;

- $\quad$ Studies that focused on the linguistics challenges of online learning;

- $\quad$ Studies that focused common ground problem in collaborative learning;

- $\quad$ Studies that focused on meanings and values that and culture dependent;

- $\quad$ Studies that focused on the intricate meaning of culture in education;

- $\quad$ Studies that focused on cross-cultural comparisons in online education;

- $\quad$ Studies that were conducted within the scope of key learning and cultural theories and frameworks; 
Studies that criticised some major learning and cultural theories and frameworks;

\subsection{Exclusion Criteria}

- $\quad$ Studies that did not associate culture to online collaborative learning

- $\quad$ Studies that did not focus on online collaborative learning

- $\quad$ Studies that did not focus on the social aspects of online learning

- $\quad$ Studies that did not focus on the linguistics challenges of online learning

- $\quad$ Studies that did not focus common ground problem in collaborative learning

- $\quad$ Studies that did not focus on meanings and values that and culture dependent

- $\quad$ Studies that did not focus on the intricate meaning of culture in education

- Studies that did not focus on cross-cultural comparisons in online education

- $\quad$ Studies that were not conducted within the scope of key learning and cultural theories and frameworks

- $\quad$ Studies that did not criticise some major learning and cultural theories and frameworks

In summary, the literature was studied with the aim of extracting emerging issues recognised as closely related to the study focus and questions from the chosen articles. Along that line of thought, a conceptualisation of how online learners (or e-learners) transform into pretenders (or e-actors) in collaborative learning emerge.

\subsection{Limitations of Using Literature Review as a Methodology}

Amid the advantages of adopting a literature review methodology, certain disadvantages also exist - and an emphasis is made below as regards the two main disadvantages. The most important disadvantage can be classified under criticism that rises due to choosing the wrong literature. The literature chosen may end up being a bad choice; rationalisations can be subjective, comprehensions cannot be misrepresented, and the scientists' bias when it comes to choosing inclusion and exclusion standards can influence the research. Based on these conclusions, an important problem of this research was to develop altogether an understanding of the issues and the contexts related to them while staying indifferent to the circumstance (Yin, 2013).

\section{Discussion Of Findings - Re-Specifying Culturally Enhanced Online Collaborative Learning}

Methodologically, to urge learners to partake in a higher order of reasoning and meaning construction, the knowledge building standards of Scardamalia \& Bereiter (2003) was suggested. One of the major standards is meaning construction dialogue, this means, to "scaffold" the kind of discussion that is essential for a specific assignment. For instance, if a proposal is made that learners argue a particularly debatable topic, the cultivation of healthy arguments can be fostered by enlightening the learners on the argumentative structure and verbal elements. Debatably, a major criticism of this model oscillates within its inability to clarify how original philosophies are formed, or how complexities of comprehending (required for proficiency) advances. Furthermore, it would appear that Scardamalia \& Bereiter (2003) model of knowledge building is implausible as it attempts to make the happenstances of collaborative learning clandestine. Arguably, these criticisms may not be the most plausible or obvious, but they are considered to be the most comprehensive and serious challenges that is worth discussing alongside the consensus of online collaborative learning. For instance, the course facilitator could show the importance of Toulmin (1958) argumentative structure, which includes the point of origin of the argument (Grounds), the act of substantiating the argument (Warrant), the point of contention (Claims) and opportunity to provide a counter-argument (Rebuttal). Learners could start making use of phrases such as "This suggestion is not conclusive because . ..", "This supporting proof is not suitable due to . ..", alternatively, "Have you deliberated on this other option?" It is important that encouragement be fostered towards meaning-making dialogue among learners when they are co-operating with each other in online learning settings, for instance when leaving comments on the forum posts of their peers. Although these examples were stated without mentioning that such works have long been in implementation by the Institute for Knowledge Innovation and Technology (IKIT), in the University of Toronto, much remains to be explored within the concept of knowledge building.

In general, it is debatably acceptable that changes in the socio-techno-spatial associations as well as in the acts of learning would, in the end, prompt a change in the social methods for learning. Cultural theories of learning are often profoundly established ideas of how learning can happen and usually remain the same regardless of any specially adopted interference or teachings. Notwithstanding, shifts can happen when sociotechno relationships and practices shift after some time. It would appear that such an as this has a better likelihood of manageability in transforming the general culture of learning, as well as beliefs of the teachers and learners because of the submersible and unavoidable enculturation approach.

\subsection{Low Order of Discourse, Low Order of Intimidation}

Normally, there appears to be lacking a higher order form of discussions, for example, contesting the research of another learner, maybe as a question mark, or arguing on forums. Although most learners would argue that 
having to edit an initial post is an evidence of higher order of discourse, it appears that a high number of learners would pretentiously claim to be happy with simply enhancing the posted articles of their peers (e-acting). Moreover, it appears that deleting the post posted by their peers would be seen as socially discourteous as shown in this quote from Lim et al. (2010):

"Some students may edit simply for editing sake, and end up deleting vital or essential information. This may dampen the enthusiasm of the student who initially wrote that information."

It would debatably appear that where there is a low order of discourse, there is likely to be a lower order of intimidation from e-learners to the e-actors.

Furthermore, as collaboration involves negotiation that takes place simultaneously, developing shared meanings and co-constructing solutions to given problems with more control placed in the hands of the group, intimidation can frustrate the coordination of group members. Clearly, the kind of intimidation that exist in online collaborative learning that is dominated by mature adults is almost invisible and psychological; and very often English language becomes a constraint in articulating this claim. The phrase 'intimidation' is not sufficient to the intention of this finding. To start with, 'intimidation' although not always appropriately, typically has a derogatory inference in this context. Learners who intimidate their peers are likely to habitually discourage the exhibition and development of their peers' abilities and self believe about a phenomenon under discussion. They often collaborate almost in a seemingly boastful manner.

\subsection{The Fear For Peers}

It is rarely the case that social presence implies supporting an 'unreasonable politeness' where learners would not be doubtful or disapproving of opinions shared for fear that they may offend their peers and weaken or prevent the growth or existence of a peer-to-peer relationship respectively. Social presence often implies building an environment that enhances and supports critical yet constructive questions, distrust and the contribution of less ambiguous and sensible ideas.

Contextually, regardless of the physiognomies used in communication, learner's impression of the social and human abilities of computer-mediated communication will be dependent on the social presence built by the lecturers/facilitators as well as the online group of learners. To further advance this notion in a debatable manner, Alghamdi et al. (2016) contested for a balanced model of social presence, where members choose styles of collaboration which compensates for the absence of communication signs. When applying a medium that on its own does not give adequate signs to encourage communication, a few learners rely on the style, content and timing of their communication to boost social presence. However, this consumes a significant amount of time, sensitivity and effort, so only some learners have the time. As such, the need is present for lecturers/facilitators to deliberate on strategies through which learners can be assisted to construct and experience social presence when learning and interacting on the web in a collaborative manner (Koschmann et al., 2011).

\subsection{Social Animals but Unsocial Method of Interaction}

According to De Castella (2013), during interactions, East Asian learners have a preference for tradition and indirect replies. Westerners (mostly American learners) on the other hand are casual, direct, and like to lead in interpersonal interactions. Open-ended participative methodologies (like collaborations with less or no structures) are not ideally suited for cultures with low vulnerability acceptance (or uncertainty avoidance). Individualistic learning methods are unproductive in more shared (or collective) cultures. Autonomous achievement-based strategies are not suitable for lecturer-led learning or affiliation-oriented cultures (De Castella, 2013). Learners from collectivist cultures are defined by mutual dependence, group character, self-discipline, and stratified control. Individualism values uniqueness, liberty and impartiality (Hewling, 2005).

Learners from attribution or status-based cultures tend to prefer more lecturer or authority-oriented learning methods. Criticism for individual progress should be unbiased, direct and fact-oriented. For learners from grouporiented cultures, the criticism is probably going to be indirect and sensitive (Edmundson, 2005). More input from the lecturer is needed in high power distance cultures.

Learners from collective culture require social orientation strategies, group work, as well as collaboration. Individualistic cultures appear to need more initiative, freedom, and open prospects (Sahlins, 2011). Orientation and directions will need to be detailed and exact for high vulnerability avoiding cultures. Low vulnerability cultures favour less direction and clarification. Learners from an emotional culture favour more collaborative methodologies. In online collaborative activities, the cultural dissimilarities in task allocation and settings usually affect the success of the activity. East Asian learners tend to accentuate the relationship with other learners regardless of their cultures. European learners are task-focused. The absence of mutual significance makes it hard to interact (De Castella, 2013).

Consequentially, whilst some of the aforementioned findings may also be typified to the context of offline collaborative learning, it is worth stating that it is not the focus of this study and thus may debatably make the findings appear only as collectivist perspectives. The findings have been helpful towards yielding insights about 
various cultural barriers that posits within the happenstances of online collaborative learning. Beyond the yielded insights, they have tended to provide an overall factorial analysis of cases or scenarios that are akin or a near match to the concept under study. Also, because culture may be unavoidably detrimental to the success of online collaboration, it is difficult to typify these findings to unforeseen or uncommon scenarios.

\section{Conclusion, Recommendation And Limitations}

Collaborating online may appear strange to some learners, which could lead to poor online interactions or absence of engagement. It is in a manner of significance worth considering how online collaborative learning situations can be deliberated and deployed as a strategy that could expand social presence. An approach that has been advised by technology enhanced learning practitioners is to stimulate the practise of using individual learner profiles and photographs, so as to help learners feel a more personalised relationship (Wickeri, 2011). The suggestions put forward in this paper via exploration found that, during online collaborative interactions, some learners found adding information and a photograph to their profile useful, and thought that it was useful to see the profiles of other learners. However, other learners felt no requirement for these practices, had concerns about privacy or agreed to the idea that reading the post of other learners was an ideal strategy to become more acquainted with them (Friedman, 2015). Possibly, this is not unexpected, and social presence should be considered as 'an inconstant feeling of others and interactions with them in intervened situations' (Signorini, 2009), as opposed to something that can be effortlessly passed on using a static individual profile.

As is regularly the situation in online learning, learners have diverse views, preferences and desires. It is just by studying how online communication for knowledge that it was discovered that the degree to which some aspects are considered useful by students (Sharples et al., 2010).

It is reasonably believed that the theoretical misunderstandings surrounding the prospects of group learning exacerbate the challenges of understanding the cultural barriers to effective collaborative learning. Since technology enhanced course facilitators and learners, for the most part, accept that learning is essentially a personal issue, they may see the attempt to study and understand the issues challenging collaborative learning to be a useless endeavour (Lim et al., 2010). Also, for researchers, the misconception of collaborative learning confuses their decisions or more specifically, their research direction, driving them to search for impacts of instructive and technological development where there is none (Haslanger, 2011). If by chance some researchers become cognisant of the fact that groups can build knowledge at a rate that surpasses the entirety of the individual inputs as well as the fact that the group learning has the power to make impact in individual learning, only then can the manifestation of genuine capability of collaborative learning be acknowledged on a larger scale. The aim of this project is to create thorough and convincing reviews of online collaborative learning to realise the shift in the cultural paradigm required to fully embrace the numerous benefits offered by online collaborative learning (Young, 2008).

Even though it can be argued that collaborative learning is underpinned by the concept of shared goals as all learners primarily want to succeed, mutually agreed participations may not be consistent across the collaboration cycle. On the major problem of the absence of substantial social presence in online collaboration, the issue of 'belongingness' becomes more pronounced as some learners may easily feel detached.

Furthermore, there exist confusions in interaction and collaboration that oscillates around language proficiency, strange sense of humour, the fear of being misunderstood and trust. From a constructivist point of view, the constructivists' emphasis on what is considered as "genuine" learning problems. Since constructivist learning designs are usually based on creating "genuine" learning tasks that are applicable and consequently appealing to learners. A significant obstacle to culturally diverse social constructivist analysis is discerning if learning tasks are "genuine" to learners from diverse cultural background.

On exploring e-learners and e-actors, two aspects were found problematic and relatively disturbing, the first is associated to how e-learners become e-actors, and the second is associated to how e-actors become e-learners. In fact, it can be said that e-learning is the early stage of e-acting, just as e-acting is the early stage of e-learning. Although, the appropriate phrase for this problem could be termed as 'analysis-paralysis'.

To this end, it is acknowledged that all studies have aspects of uncertainty that is why it is crucial to analyse it in almost all its entirety. Although this study attempted to explore the unobvious aspects of cultural barriers impacting online collaborative learning, its finding exists not without its limitations. Therefore, much remains to be explored about if culture impacts online collaborative learning in isolation or if there are hidden drivers embedded within a culture that together impacts online collaborative learning.

\section{References}

Alghamdi, M., Regenbrecht, H., Sydney, S., Langlotz, T. and Aldridge, C. (2016). SOCIAL PRESENCE AND MODE OF VIDEOCOMMUNICATION IN A COLLABORATIVE VIRTUAL ENVIRONMENT.

Arkoudis, S., Yu, X., Baik, C., Chang, S., Lang, I., Watty, K., Borland, H., Pearce, A. and Lang, J. (2010). Finding common ground: Enhancing interaction between domestic and international students-Guide for 
academics. Australian Learning and Teaching Council.

Barkley, E.F., Cross, K.P. and Major, C.H. (2014). Collaborative learning techniques: A handbook for college faculty. John Wiley \& Sons.

Bodemer, D. and Dehler, J. (2011). Group awareness in CSCL environments. Computers in Human Behavior, 27(3).

Capdeferro, N. and Romero, M. (2012). Are online learners frustrated with collaborative learning experiences?. The International Review of Research in Open and Distributed Learning, 13(2)

Chen, S. J., Hsu, C.L., \& Caropreso, E. J. (2006). Cross-cultural collaborative online learning: When the West Meets the East. International Journal of Technology in Teaching and Learning, 2(1), 17-35.

Clark, H.H. and Brennan, S.E. (1991). Grounding in communication. Perspectives on socially shared cognition, 13(1991), pp.127-149.

Cresswell, J. (2009). Research design: Qualitative, quantitative, and mixed methods approaches. Thosands Oaks, CA: Sage.

De Castella, K., Byrne, D. and Covington, M., (2013). Unmotivated or motivated to fail? A cross-cultural study of achievement motivation, fear of failure, and student disengagement. Journal of Educational Psychology, 105(3), p.861.

Edmundson, A. (2007). The Cultural Adaptation Process (CAP) Model: Designing E-Learning for Another Culture. In A. Edmundson (Ed.), Globalized E-Learning Cultural Challenges (pp. 267-290). Hershey PA: Information Science Publishing.

Foster, M., Macdonald, I. and Firth, R., 2014. Re-structuring 'culture of learning': exploring international student mobility experiences in China and the UK through a non-essentialist lens. Journal of Intercultural Education.

Friedman, J. (2015). Globalization, class and culture in global systems. journal of world-systems research, 6(3), pp.636-656.

Gar?nkel, H. (1967). Studies in ethnomethodology.

Hadwin, A.F., Järvelä, S. and Miller, M. (2011). Self-regulated, co-regulated, and socially shared regulation of learning. Handbook of self-regulation of learning and performance, 30, pp.65-84.

Haslanger, S. (2011). Ideology, generics, and common ground. In Feminist Metaphysics (pp. 179-207). Springer Netherlands.

Hewling, A. (2005). Culture in the online class: Using message analysis to look beyond nationality-based frames of reference. Journal of Computer-Mediated Communication, 11(1). Retrieved from http://jcmc.indiana.edu/voll1/issue1/hewling.html.

Hofstede, G. (1986). Cultural differences in teaching and learning. International Journal of intercultural relations, 10(3), pp.301-320.

Järvelä, S. and Hadwin, A.F. (2013). New frontiers: Regulating learning in CSCL. Educational Psychologist, 48(1).

Kaye, A.R. ed. (2012). Collaborative learning through computer conferencing: the Najaden papers (Vol. 90). Springer Science \& Business Media.

Koschmann, T., LeBaron, C., Goodwin, C. and Feltovich, P. (2011). "Can you see the cystic artery yet?" A simple matter of trust. Journal of Pragmatics, 43(2), pp.521-541.

Kouzakova, M., Ellemers, N., Harinck, F. and Scheepers, D. (2012). The Implications of Value Conflict How Disagreement on Values Affects Self-Involvement and Perceived Common Ground. Personality and Social Psychology Bulletin, 38(6), pp.798-807.

Kumar, V.S., Gress, C.L., Hadwin, A.F. and Winne, P.H. (2010). Assessing process in CSCL: An ontological approach. Computers in Human Behavior, 26(5).

Lim, W.Y., So, H.J. and Tan, S.C. (2010). eLearning 2.0 and new literacies: are social practices lagging behind?. Interactive Learning Environments, 18(3), pp.203-218.

Masuda, T., \& Nisbett, R.E. (2001). Attending holistically versus analytically: Comparing the context sensitivity of Japanese and Americans. Journal of Personality and Social Psychology, 81(5), 922-934.

McSweeney, B. (2002). Hofstede's model of national cultural differences and the consequences. A triumph of faith -- a failure of analysis. Human relations, 55, 89-111.

Morse, K. (2003). Does one size ?t all? Exploring asynchronous learning in a multicultural environment. Journal of Asynchronous Learning Networks, 7(1), 37-55.

Nisbett, R. E. (2003). The geography of thought: How Asians and Westerners think differently ... and why. New York: Free Press.

Patton, M. (2002). Qualitative research and evaluation methods. Thousand Oaks, CA: Sage.

Phielix, C., Prins, F.J. and Kirschner, P.A. (2010). Awareness of group performance in a CSCL-environment: Effects of peer feedback and reflection. Computers in Human Behavior, 26(2).

Poulis, K. Poulis, E. and Plakoyiannaki, E. (2013). The role of context in case study selection: An international 
business perspective. International Business Review, 22(1), pp.304-314.

Rogat, T.K. and Linnenbrink-Garcia, L. (2011). Socially shared regulation in collaborative groups: An analysis of the interplay between quality of social regulation and group processes. Cognition and Instruction, 29(4), pp.375-415.

Sahlins, M. (2011, March). Only Apes Have 'Human Nature.' Lecture delivered at the University of British Columbia, Vancouver BC.

Scardamalia, M., \& Bereiter, C. (2003). "Knowledge Building". In: J. W. Guthrie (Ed.), Encyclopedia of Education. 2nd edition. New York: Macmillan Reference, USA.

Schegloff, E.A. (1991). Reflections on talk and social structure. Talk and social structure: Studies in ethnomethodology and conversation analysis, pp.44-70.

Sharples, M., Taylor, J. and Vavoula, G. (2010). A theory of learning for the mobile age. In Medienbildung in neuen Kulturräumen (pp. 87-99). VS Verlag für Sozialwissenschaften.

Signorini, P., Wiesemes, R., \& Murphy, R. (2009). Developing alternative frameworks for exploring intercultural learning: a critique of Hofstede's cultural difference model. Teaching in Higher Education, 14(3), 253-264.

Toulmin, S. (1958). The uses of argument. Cambridge, UK: Cambridge University Press

Vatrapi, R.V. (2008). Cultural Considerations in Computer Supported Collaborative Learning. Research and Practice in Technology Enhanced Learning, 3(2), 159-201.

Wickeri, P.L. (2011). Seeking the common ground: Protestant Christianity, the Three-Self Movement, and China's united front. Wipf and Stock Publishers.

Xu, S. and Connelly, M. (2010). Narrative inquiry for school-based research. Narrative Inquiry, 20(2), pp.349370.

Yin, R. (2013). Case study research: Design and methods. Sage publications.

Young, P. A. (2008). The Culture Based Model: Constructing a Model of Culture. Educational Technology \& Society, 11(2), 107-118.

Zhu, C. (2012). Student Satisfaction, Performance, and Knowledge Construction in Online Collaborative Learning. Educational Technology \& Society, 15(1).

Anietie Ukpabio, BSc (Hons), MSc, MBA, Cert Ed, MABE, MBCS, QTLS, FHEA I am a PhD Researcher at Lancaster University and a certified Business Analyst at IBM Client Innovation Centre.

My major interest posits in conducting research into the connections between our material surroundings, the technologies (beyond computers) that permeate them, and the ways we act, think and learn. Two recurring interests are how institutions design and evaluate their built environment domain to support opportunities for learning. More general interests include Activity Theory, networked and collaborative learning. Additionally, I also am concerned with collaborative work and group discussion in digitally-mediated environments, with a theoretical and practical commitment to social justice and equity within learning communities. I am interested in understanding the ways that sociocultural and sociotechnical elements inherent in applications of digital education operate to marginalise students who fall outside the ideations of dominant ideology.

Apart from my previous software and IT industry experience, I am also a qualified teacher and my previous teaching background involves being a former Computing Lecturer at East Kent College, New Vic College and City College Norwich.

My major qualifications are a first class honours degree in Computing from the University of Greenwich, an MSc. distinction in Information Technology from the Cardiff Metropolitan University, an MBA from University of Northampton.

Acknowledgement: This research was undertaken as part of the $\mathrm{PhD}$ in E-research and Technology Enhanced Learning in the Department of Educational Research at Lancaster University. I am pleased to acknowledge the contribution of lecturers and peers in supporting the development of this study and its report as an assignment paper. 